\title{
EFICIÊNCIA ENERGÉTICA
}

\section{Na IluminaÇÃo PÚBlica}

\section{Introdução}

A iluminação pública é responsável por $3 \%$ do consumo de energia elétrica, em Portugal, tendo havido um crescimento no consumo de energia elétrica neste setor, entre 2000 e 2011, de cerca de 55\%, com uma taxa média de crescimento anual de cerca de $5,1 \%$. No ano de 2011 , os custos com a iluminação pública rondaram os $170 \mathrm{M} €$, sendo que grande parte foram assegurados pelos Municípios.

Atendendo ao panorama financeiro delicado de grande parte das autarquias do País, e sabendo que a iluminação pública tem um peso considerável nas despesas anuais de energia, faz sentido que se concentre aqui um esforço para tornar mais eficientes estas instalações.

A nível nacional, a Estratégia Nacional para a Energia 2020 (ENE 2020) define estratégias que visam o cumprimento das medidas impostas pela União Europeia no sentido de cumprir objetivos que respeitem a sustentabilidade
A ENE 2020 define uma agenda para a competitividade, o crescimento e a independência energética e financeira do país através da aposta nas energias renováveis e da promoção integrada da eficiência energética, assegurando a segurança de abastecimento e a sustentabilidade económica e ambiental do modelo energético. Um dos eixos em que se divide a ENE 2020 visa diretamente a promoção da eficiência energética na lluminação Pública (IP), com o objetivo de promover e apoiar projetos inovadores de iluminação pública com prioridade para os centros históricos.

Existem no mercado diversas soluções e tecnologias que permitem melhorar a eficiência energética da IP, facilitando uma gestão mais eficiente.

Estes sistemas podem também permitir economias diretas nos consumos de energia e/ou levar a um aumento da vida útil das lâmpadas, permitindo uma redução dos custos de manutenção das instalações de IP.

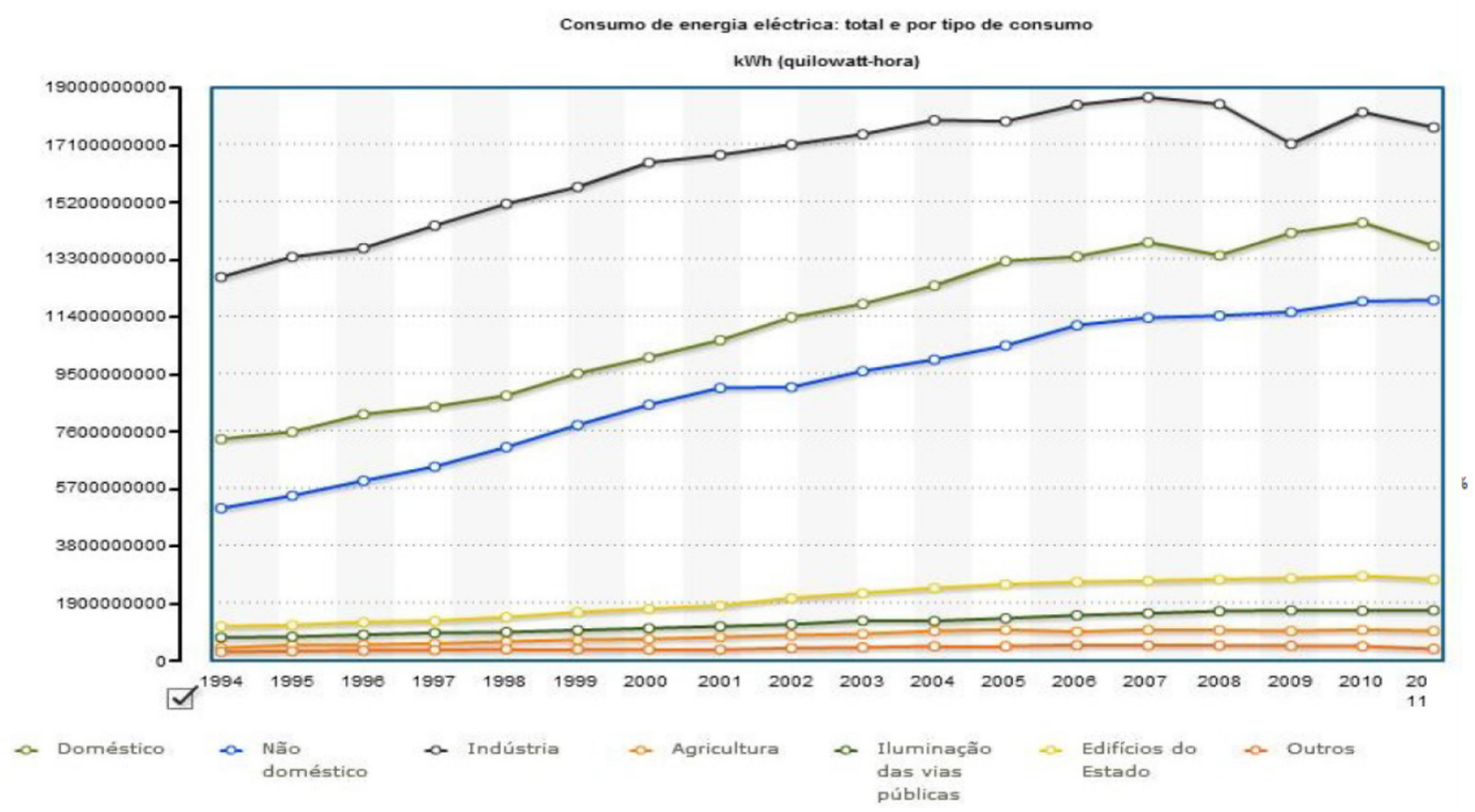




\section{Panorama atual da IP}

A Iluminação Pública é essencial para o desenvolvimento social e económico das sociedades e para o aumento da qualidade de vida das pessoas. A iluminação pública está diretamente ligada à segurança da via pública, sendo uma das características em destaque nas cidades, permitindo o reconhecimento dos espaços públicos e a orientação de trajetos, quando aplicada à iluminação rodoviária. A pesar de nos primórdios da iluminação pública, ela ter uma função muito importante relacionada com a segurança das pessoas, hoje em dia essa função começa a desvanecer-se, embora não haja dúvidas que um local bem iluminado é muito mais confortável que um local escuro.

A lluminação Pública (Urbana) está diretamente relacionada com a iluminação publicitária, com a iluminação exterior de arquitetura e com a iluminação das vias e espaços públicos.

Não existe documentado o número exato de pontos de luz associados à iluminação pública, mas prevê-se que se situe, em Portugal, entre os 3 e os 4 milhões.

Deixando de fora deste artigo a iluminação publicitária, as soluções habitualmente utilizadas no mercado da iluminação pública são as seguintes:

\section{- Mercúrio \\ - Sódio de baixa pressão \\ - $\quad$ Sódio de alta pressão \\ - lodetos metálicos \\ - LED's}

Embora ainda possam existir na atual infraestrutura de iluminação pública, as soluções de mercúrio estão proibidas do mercado da UE desde 2010, não podendo ser utilizadas em novas instalações. Este facto deve-se principalmente à sua baixa eficiência energética e elevada toxicidade.

A tecnologia mais utilizada atualmente é a de sódio de alta pressão (HPS - High-Pressure Sodium).

Mais recentemente, e com o desenvolvimento da tecnologia, é possível aplicar a tecnologia LED à iluminação pública, mediante a combinação de um determinado número de díodos, que permitem obter, no final, as características e requisitos de iluminação adequados a um determinado local.

\section{Lâmpadas de vapor de mercúrio (HPM)}

Este tipo de lâmpada tem como princípio de funcionamento a descarga entre dois elétrodos, localizados no interior de um tubo no qual existe uma mistura de mercúrio, sob alta pressão, e árgon. Durante o processo de aquecimento, o mercúrio vaporiza-se gradualmente, sendo emitida uma luz de fraca intensidade. Alguns modelos têm também uma camada de pó fluorescente, com o intuito de produzir radiação vermelha na parte interior do invólucro, cujo objetivo é transformar parte da radiação ultravioleta (UV) emitida em luz visível. Esta prática constitui uma melhoria significativa no aspeto da luz emitida, mas não se traduz numa melhoria expressiva do rendimento luminoso nem do índice de reprodução de cor (IRC). Existem também lâmpadas de luz mista em que o tubo de descarga com o mercúrio se encontra ligado um filamento de lâmpada incandescente, como forma de melhoramento do espectro luminoso. No entanto, para evitar a redução drástica da vida útil da lâmpada, é necessário reduzir a temperatura de funcionamento do filamento, o que leva, inerentemente a uma redução do rendimento luminoso.

Neste tipo de lâmpadas apenas 15\% da energia é convertida em radiação visível, sendo os restantes $85 \%$ transformados em perdas por convecção e condução e em radiação IV e UV.

Como equipamentos auxiliares é necessário o balastro e o condensador.

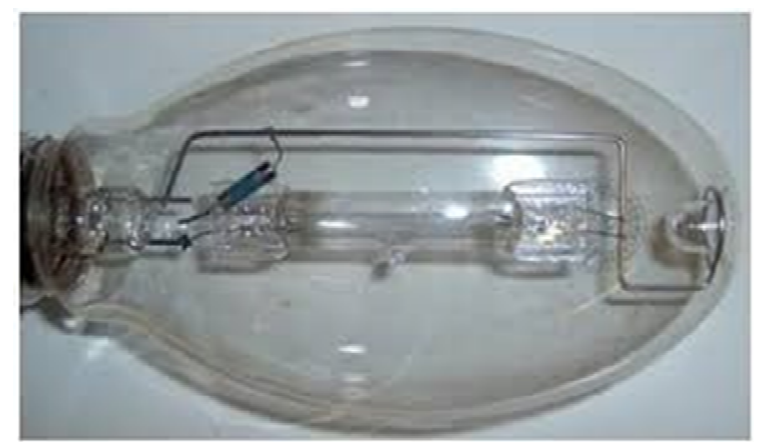




\section{Lâmpadas de vapor sódio de baixa pressão}

As lâmpadas de vapor de sódio de baixa pressão têm como princípio de funcionamento a descarga num tubo de vidro especial em forma de $U$, contendo uma atmosfera composta de néon e árgon, além do sódio, onde se forma o arco elétrico, com um elétrodo em cada extremidade, desenhado para refletir a radiação infravermelha (IV), cujo objetivo é garantir uma temperatura suficientemente elevada para que seja possível a vaporização do sódio, permitindo assim a emissão de luz visível.

As LPS constituem a fonte de luz mais eficiente entre todas as lâmpadas, no que respeita a consumos energéticos e iluminação produzida, dado o seu elevado rendimento luminoso e longo período de duração de vida.

Este tipo de lâmpadas possui a capacidade de manter um fluxo luminoso constante ao longo da sua vida útil, aumentando ligeiramente o consumo à medida que se aproxima do fim de vida. Tem um rendimento luminoso muito elevado, no entanto devido a apresentar um espectro monocromático na faixa do amarelo, tem um índice de restituição de cor muito baixo, próximo de zero, e uma temperatura na ordem dos $1800^{\circ} \mathrm{K}$ e os 2000 K. Em termos tempo de vida útil o seu desempenho não é brilhante, situando-se em média, nas 16000 horas.

Para o seu funcionamento é necessário o arrancador, o balastro e condensador como equipamentos auxiliares.

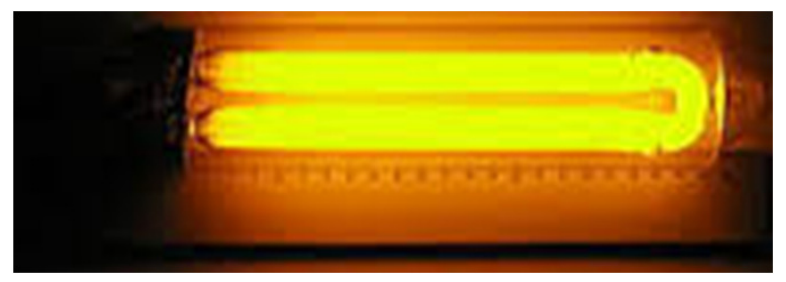

\section{Lâmpadas de vapor sódio de alta pressão}

Neste tipo de lâmpada, uma pequena quantidade de sódio misturada com mercúrio é colocada numa cápsula de vidro contendo xénon no seu interior. Durante o processo de aquecimento da lâmpada, o sódio e mercúrio vaporizam-se gradualmente, fazendo com que a lâmpada emita uma luz ténue e, à medida que a pressão vai aumentando, a intensidade de luz vai igualmente aumentando, até estabilizar. Quanto maior for a potência da lâmpada, maior será a temperatura no seu interior e quanto maior for a temperatura, maior será a pressão do vapor e menor a resistência elétrica da lâmpada.

Este tipo de lâmpada emite radiação em grande parte do espectro visível, cerca de $30 \%$, e muito pouca radiação na região dos UV. A luz emitida tem cor amarelada, com temperatura de cor entre os 2000 ㅇ e os 3200 ㅇ K e com um índice de restituição de cor entre os 20 e os 70 .

Tal como as lâmpadas de vapor de sódio de baixa pressão, necessitam de balastro, arrancador e condensador como equipamentos auxiliares.

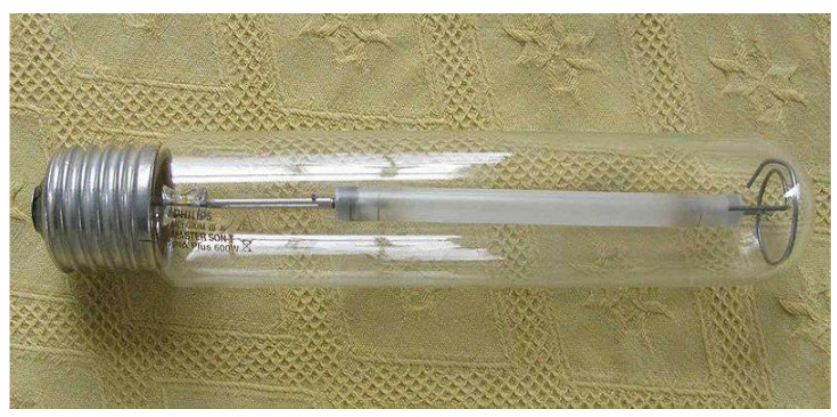

\section{Lâmpadas de iodetos metálicos}

Este tipo de lâmpada tem, essencialmente, a mesma constituição que as lâmpadas de vapor de mercúrio, diferindo na mistura de substâncias contida no tubo de descarga. Nas lâmpadas de iodetos metálicos são adicionadas ao mercúrio misturas com emissores iónicos ou com emissores moleculares, obtendo-se uma emissão de luz com um espectro de riscas ou contínuo, respetivamente.

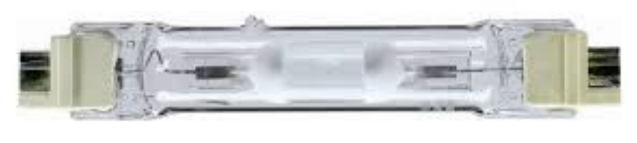


Este tipo de lâmpada possui um elevado rendimento luminoso, apesar de inferior aos das lâmpadas de vapor de sódio, e apresenta uma excelente restituição cromática. A luz emitida é clara, semelhante à luz do dia, com uma

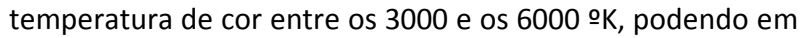
alguns equipamentos possuir temperaturas um pouco superiores. No entanto, a cor é afetada pelas horas de utilização do equipamento, possuindo uma duração média de utilização a rondar as 9000 horas.

\section{Lâmpadas LED}

O LED é baseado no díodo semicondutor, que quando polarizado, faz com que os eletrões se recombinem no interior do dispositivo, libertando energia na forma de fotões. A luz é emitida numa banda espectral relativamente estreita e é produzida pelas interações energéticas dos eletrões.

Os leds já são usados há muito tempo e com sucesso nos mais diversos equipamentos eletrónicos. Mais recentemente começaram a ser usados na sinalização viária e agora está-se a evoluir para a sua aplicação na iluminação pública.

Os LED's de cor branca tem vindo a evoluir rapidamente, quer em potência, quer em restituição cromática, de tal forma que, hoje em dia, já conseguem ser uma alternativa à iluminação convencional em todas as suas vertentes.

A quantidade de luz emitida por um LED é conhecida como fluxo luminoso e é medido em lúmen ( $\mathrm{Im})$. O fluxo luminoso depende da cor e da densidade de corrente elétrica que alimenta o LED. Quanto mais corrente o chip semicondutor do LED conseguir administrar, mais fluxo luminoso será emitido. No entanto, a eficiência da transformação da corrente em luz é reduzida.

Atualmente os LED's emitem um fluxo luminoso que ronda os $150 \mathrm{~lm} / \mathrm{W}$ e com potência, por LED, de 1,0 - 5,0 watts, disponíveis em várias cores, responsáveis pelo aumento considerável na substituição de alguns tipos de lâmpadas em várias aplicações de iluminação.
No entanto uma das grandes limitações deste tipo de tecnologia é a temperatura de funcionamento e o calor que é gerado quando em funcionamento, obrigando os fabricantes a ter especial atenção aos dissipadores que associam às luminárias.

Um outro problema é o diminuto angulo de abertura do feixe, problema que é ultrapassado através de refletores.

A manutenção do fluxo luminoso é expresso em horas e é definido da forma LxBy, onde $x$ representa a percentagem de luz emitida pelo LED, e y representa o número de LED's que deixaram de cumprir os critérios mínimos. Para os LED's é normal considerar 60000 horas L70B10, isto significa que após 60000 horas de uso a luminária LED vai fornecer $70 \%$ do seu fluxo luminoso e que apenas $10 \%$ dos LED's não atingirá esse nível.

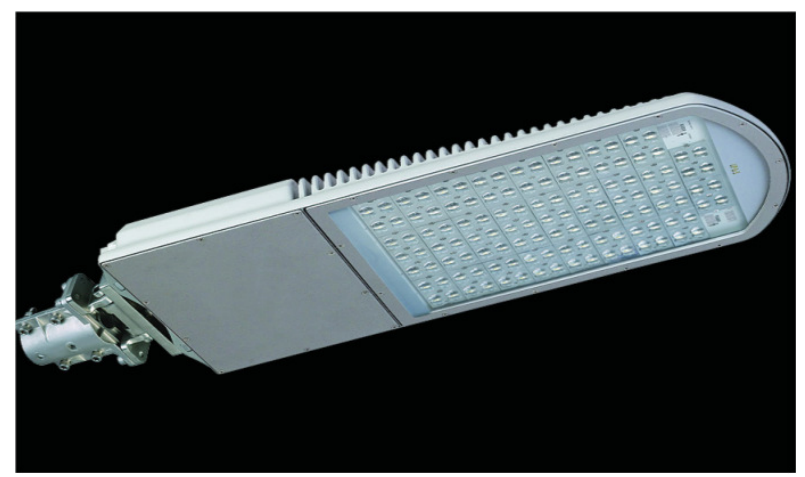

3. Metodologias para atingir a eficiência

A Estratégia Nacional para a Energia, ENE 2020, sugere a aposta nas energias renováveis e na promoção integrada da eficiência energética como forma de se atingir a competitividade, o crescimento e a independência energética do país.

Também como consequência da aplicação do Plano Nacional de Ação para a Eficiência Energética (PNAEE) e da ENE 2020, - Programa de Eficiência Energética na Administração Pública - ECO.AP pretende que se obtenha, até 2020, nos serviços públicos e nos organismos da Administração Pública, um nível de eficiência energética na ordem dos $20 \%$. 
Para se concretizarem tais objetivos, será necessário utilizar racionalmente a energia, melhorar a eficiência energética das instalações semafóricas e aumentar a eficiência energético-ambiental dos equipamentos de IP.

Cabe aos Municípios, através do seu relacionamento com a entidade distribuidora de energia, a responsabilidade de assegurar o bom funcionamento e avaliar o desempenho da IP. Este último aspeto revela-se particularmente importante no contexto das finanças autárquicas, pelo que as nossas cidades pretendem, atualmente, encontrar soluções para a redução do consumo de energia e custos manutenção associados às instalações de IP.

Como soluções que têm vido a ser adotadas na IP, como forma de se melhorar a eficiência destacam-se as seguintes:

\section{Substituição das lâmpadas}

Substituição das antigas lâmpadas de vapor de mercúrio por lâmpadas mais eficientes. Usualmente a substituição é por lâmpadas de vapor de sódio de alta pressão, no entanto, há situações em que é alterada toda a filosofia de iluminação, podendo ser adotadas soluções mais modernas, que levam à substituição de toda a luminária.

\section{Balastros Eletrónicos/Regulação de fluxo}

A regulação de fluxo é também uma forma de se conseguir reduzir os gastos com a energia elétrica associada à iluminação pública, isto porque é conhecido que em muitos casos a iluminação pública está sobre dimensionada e não necessita de estar ligada à potência nominal durante a totalidade do período de funcionamento.

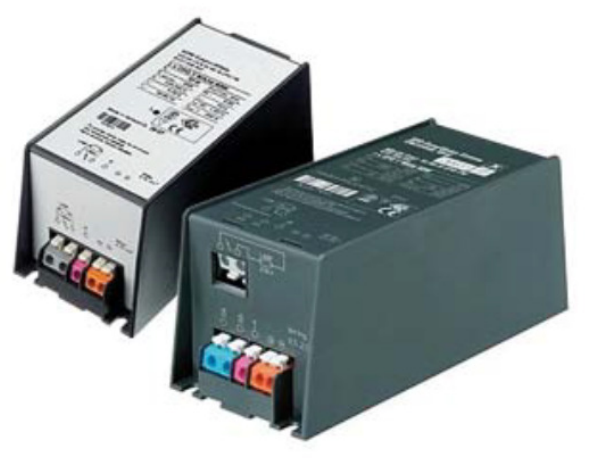

A possibilidade de se reduzir o fluxo luminoso durante determinados períodos noturnos garante economias no consumo de energia elétrica, conservando-se sempre um nível de segurança para os utentes.

Os reguladores de fluxo são equipamentos que permitem fazer a função função dimming. Esta poderá ser realizada pela variação por patamares ou de uma forma contínua. De um modo geral, podemos relacionar esta função com a densidade de tráfego, as condições atmosféricas locais, a adaptabilidade aos parâmetros locais do projeto de iluminação, o fator de manutenção do fluxo luminoso da lâmpada e determinada programação horária (pré-definida ou parametrizável).

Uma outra solução que poderá ser adotada é a utilização de balastros eletrónicos de duplo nível. Esta tecnologia tem como vantagens o baixo consumo, o elevado fator de potência e a capacidade de absorver variações de tensão da rede. Consegue reduzir a potência em cerca de $40 \%$ e substitui o arrancador e condensador das luminárias tradicionais.

A elevada eficiência, as perdas reduzidas e a elevada capacidade de controlo do fluxo luminoso, são vantagens muito importantes desta tecnologia.

A utilização dos balastros eletrónicos associados a outros dispositivos de poupança de energia, tais como, reguladores de fluxo e sensores de presença e luminosidade, podem levar a poupanças de energia na ordem dos $75 \%$.

\section{LED's}

A utilização da tecnologia LED na iluminação pública começa a ser uma alternativa muito interessante, com a evolução da tecnologia associada à diminuição dos preços das luminárias.

Se na iluminação pública não viária esta tecnologia encontrase já muito implementada, na iluminação viária ela ainda não consegue superar a tradicional utilização do vapor de sódio de alta pressão. 


\section{ARtigo TéCnico}

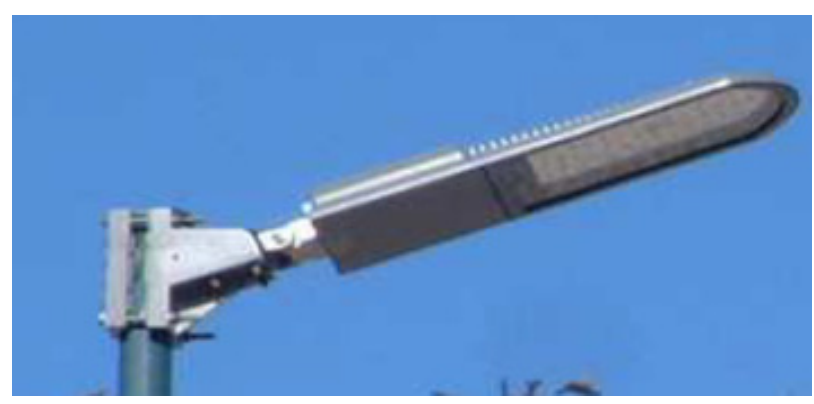

Se a redução efetiva dos consumos, o elevado índice de restituição de cores, a flexibilidade na temperatura da cor, a capacidade de arranque imediato, a robustez e uma vida útil muito superior às restantes tecnologias são os pontos fortes desta tecnologia, o custo das luminárias, a ainda pouca oferta de opções comerciais credíveis e a incerteza da fiabilidade por serem equipamentos com muita eletrónica expostos a condições climatéricas adversas, são os pontos fracos deste tipo de iluminação.

\section{Conclusão}

Os custos com a energia elétrica associados à iluminação pública são cada vez mais importantes e assumem um peso considerável nas autarquias e outras instituições públicas, que têm obrigatoriedade de a manter como forma de assegurar a qualidade de vida e serviços e a segurança das pessoas e bens.

Existem muitas formas de tornar estas instalações mais eficientes e com isso conseguir poupanças, no entanto, quase todas obrigam a algum investimento.

Acima de tudo é preciso pensar os projetos de iluminação pública na vertente da eficiência sem que com isso se descurem os aspetos técnicos e regulamentares associados a cada tipo de via ou espaço público.

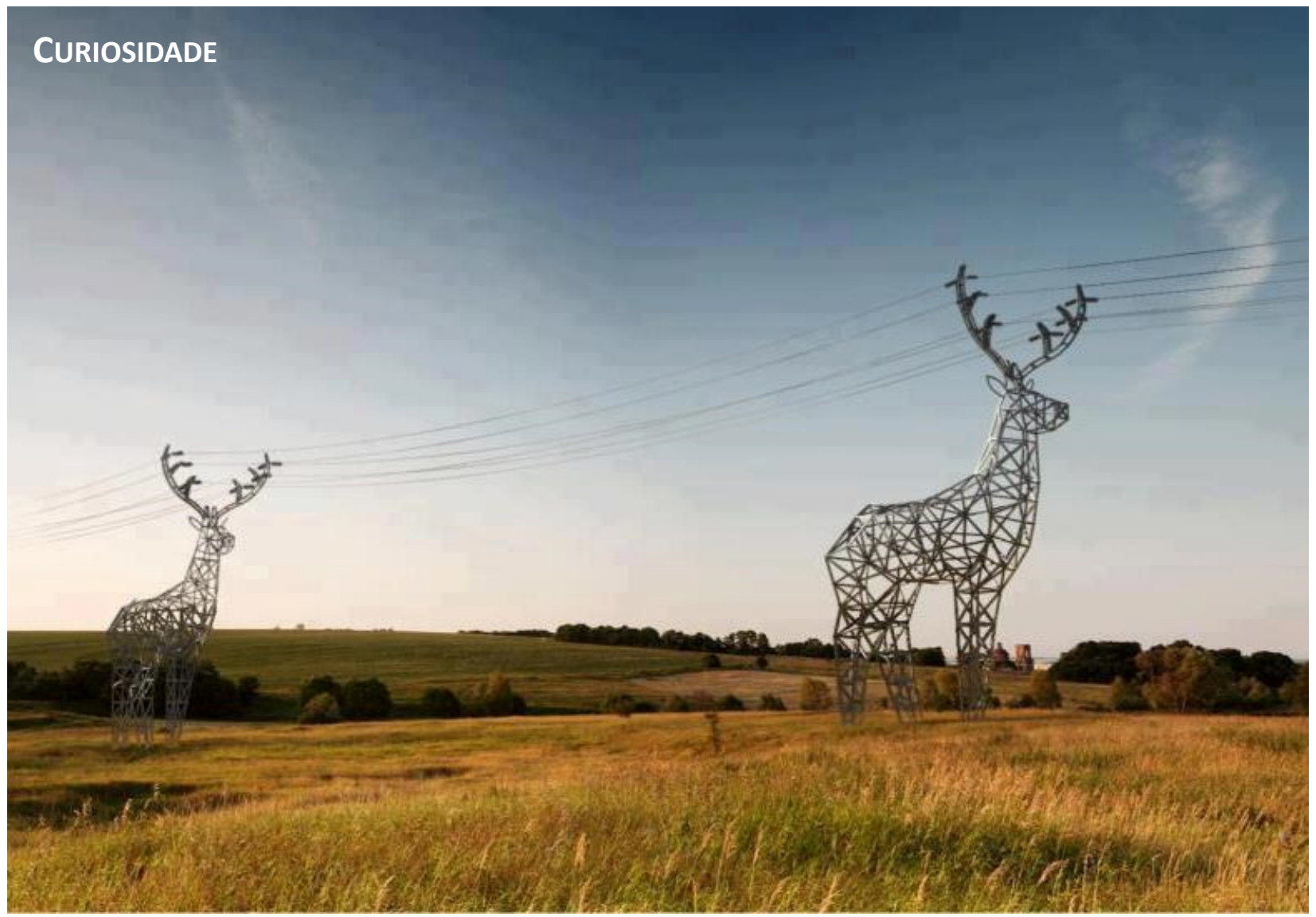

